\title{
Error Modeling and Accuracy of TAU Robot
}

\author{
Hongliang Cui, Zhenqi Zhu, \\ Zhongxue Gan and \\ Torgny Brogardh
}

\section{Introduction}

The TAU parallel configuration is rooted in a series of inventions and was masterminded by Torgny Brogardh [1][2][3][4]. The configuration of the robot simulates the shape of " $\tau$ " like the name of the Delta after the " $\nabla$ " shape configuration of another parallel robot.

As shown in Fig. 1, the basic TAU configuration consists of 3 driving axes, 3 arms, 6 linkages, 12 joints and a moving (tool) plate. There are 6 chains connecting the main column to the end-effector in TAU configuration. The TAU robot is a typical 3/2/1 configuration. There are 3 parallel and identical links and another 2 parallel and identical links. Six chains will be used to derive all kinematic equations. Table 1 highlights the features of the TAU configuration.

On the subject of D-H modeling, Tasi [5], Raghavan [6], Abderrahim and Whittaker[12] have applied the method and studied the limitations of various modeling methods. On the subject of forward kinematics, focus has been on finding closed form solutions based on various robotic configurations, and numerical solutions for difficult configurations of robots. It can be found in the work done by Dhingra [8], Shi [14], Didrit [16], Zhang [17], Nanua [18], Sreenivasan [19], Griffis and Duffy [20], Lin [21]. On the subject of error analysis, Wang and Masory [7], Gong [11], Patel and Ehmann [13] used forward solutions to obtain errors. Jacobian matrix was also used in obtaining errors. On the subject of the variation of parallel configurations, from the work done by Dhingra [9][ 10], Geng and Haynes [15], the influence of the configurations on the methods of finding closed form solutions can be found.

In this paper, the D-H model is used to define the TAU robot, a complete set of parameters is included in the modeling process. Kinematic modeling and error modeling are established with all errors using Jacobian matrix method for the TAU robot. Meanwhile, a very effective Jacobian Approximation Method is introduced to calculate the forward kinematic problem instead of Newton-Raphson method. It denotes that a closed form solution can be obtained instead of a numerical solution. A full size Jacobian matrix is used in carrying out error analysis, error budget, and model parameter estimation and identification. Simulation results indicate that both Jacobian matrix and Jacobian

Approximation Method are correct and have an accuracy of micron meters. ADAMS simulation results are used in verifying the established models.

Source: Parallel Manipulators, New Developments, Book edited by: Jee-Hwan Ryu, ISBN 978-3-902613-20-2, pp. 498, April 2008, I-Tech Education and Publishing, Vienna, Austria 


\begin{tabular}{|c|c|c|c|}
\hline & Serial Robot & Stewart Platform & Tau configuration \\
\hline Stiffness & Low & High & High (simulation) \\
\hline Accuracy & Low & High & High (simulation) \\
\hline Workspace & Large & Small & Large \\
\hline Footprint & Small & Large & Small \\
\hline Inverse solution in general & Easy & Easy & Difficult \\
\hline Analytical inverse solution & Easy & Easy & Easficult \\
\hline Forward solution in general & Easy & Difficult & Easy \\
\hline Analytical forward solution & Easy & Difficult & \\
\hline
\end{tabular}

Table 1. Comparison of kinematic properties of TAU and other robots.

\section{Link 1 of lower arm 3}

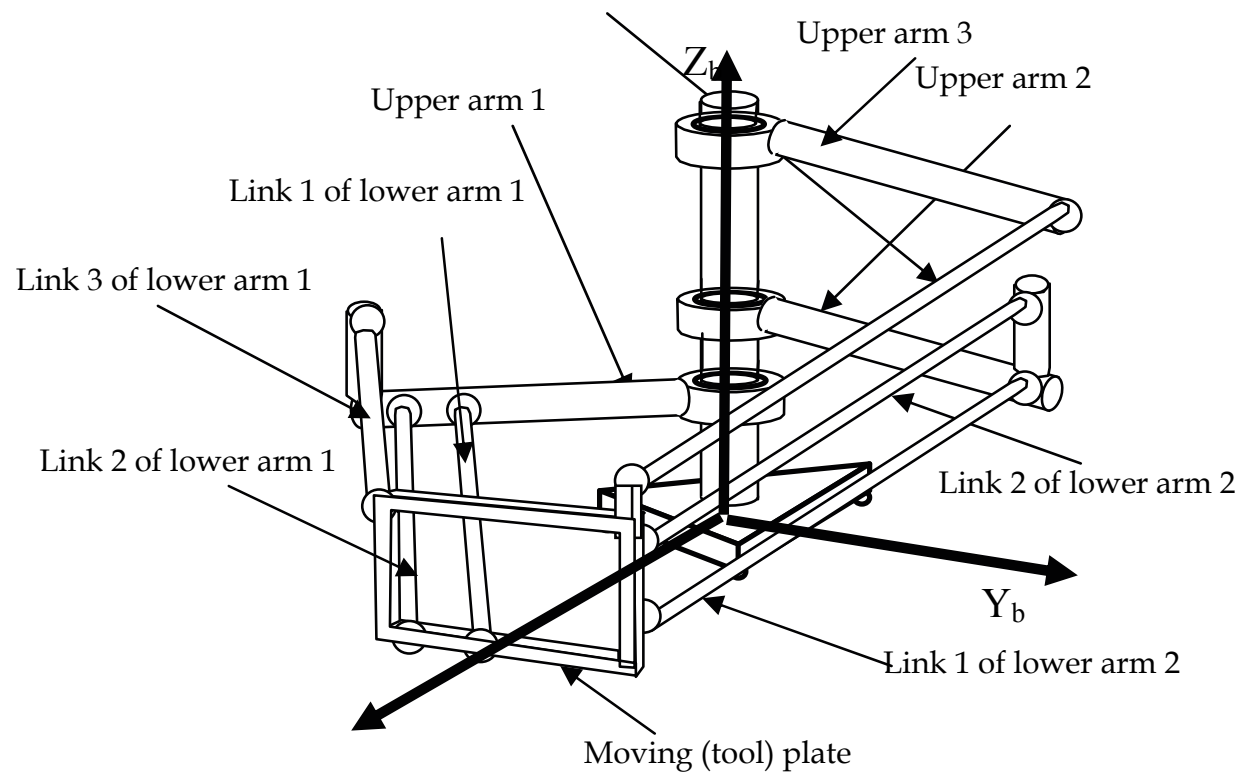

Fig. 1 TAU robot configuration 


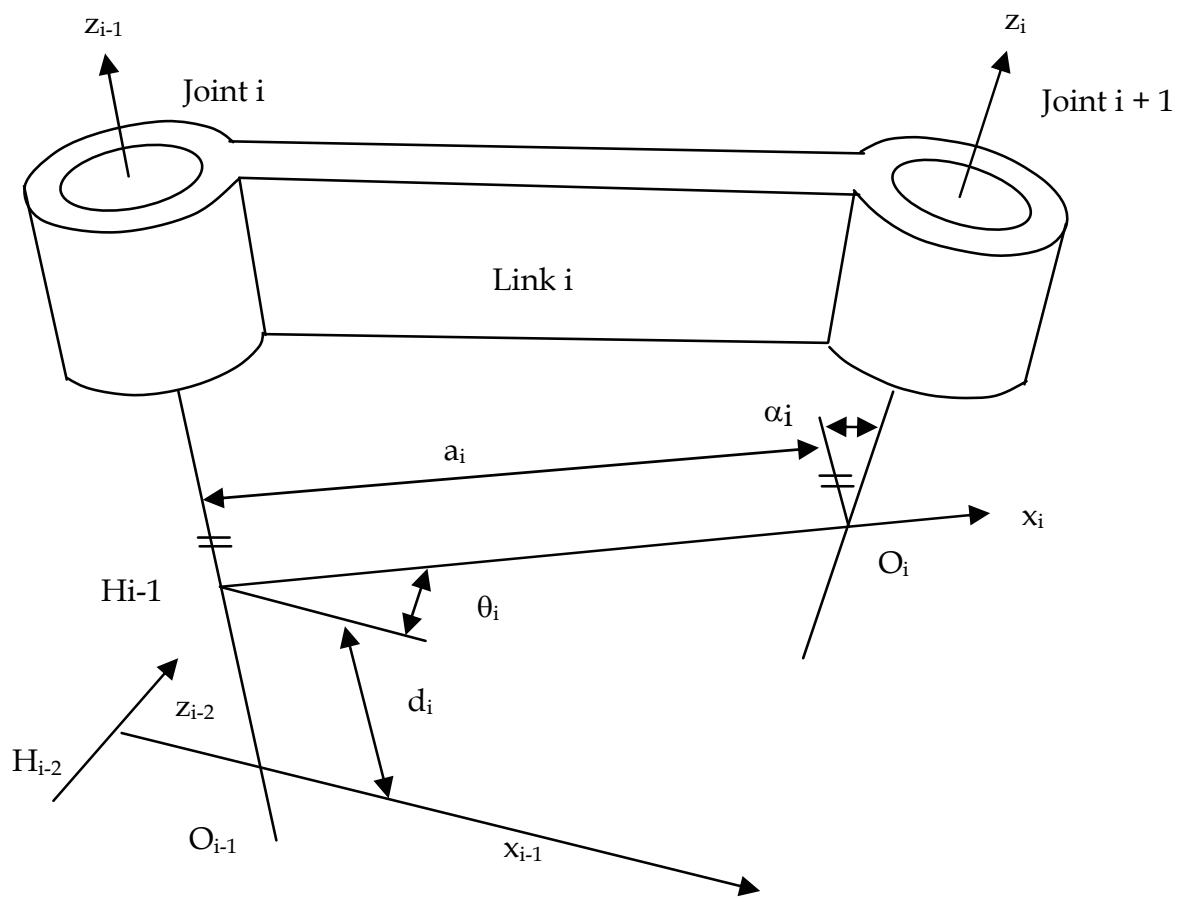

Fig. 2 Parameter definition of D-H model

\section{Kinematic modeling}

\subsection{The D-H model of TAU robot}

For the TAU robot, the D-H model is used for the following purposes:

(1) Fully describing the kinematic positional relationship among all the links and joints.

(2) Accurately and easily integrating the error model into a full parameter model.

(3) Standardizing and parameterizing the TAU model to establish dynamic coupling control model.

With the parameters defined in Fig. 2, the D-H model transformation matrix can be obtained as follows

$$
A=\left[\begin{array}{cccc}
\cos \theta_{i} & \sin \theta_{i} & 0 & -a_{i} \\
-\cos \alpha_{i} \sin \theta_{i} & -\cos \alpha_{i} \sin \theta_{i} & \sin \alpha_{i} & -d_{i} \sin \alpha_{i} \\
\sin \alpha_{i} \sin \theta_{i} & -\cos \alpha_{i} \sin \theta_{i} & \cos \alpha_{i} & -d_{i} \cos \alpha_{i} \\
0 & 0 & 0 & 1
\end{array}\right]
$$




\subsection{Inverse kinematics and forward kinematics}

For the TAU robot, the inverse kinematic and forward kinematic are relatively simple. The six equations of kinematic chains remain 3, as shown in Fig. 3, based on the condition of parallel and identical links.

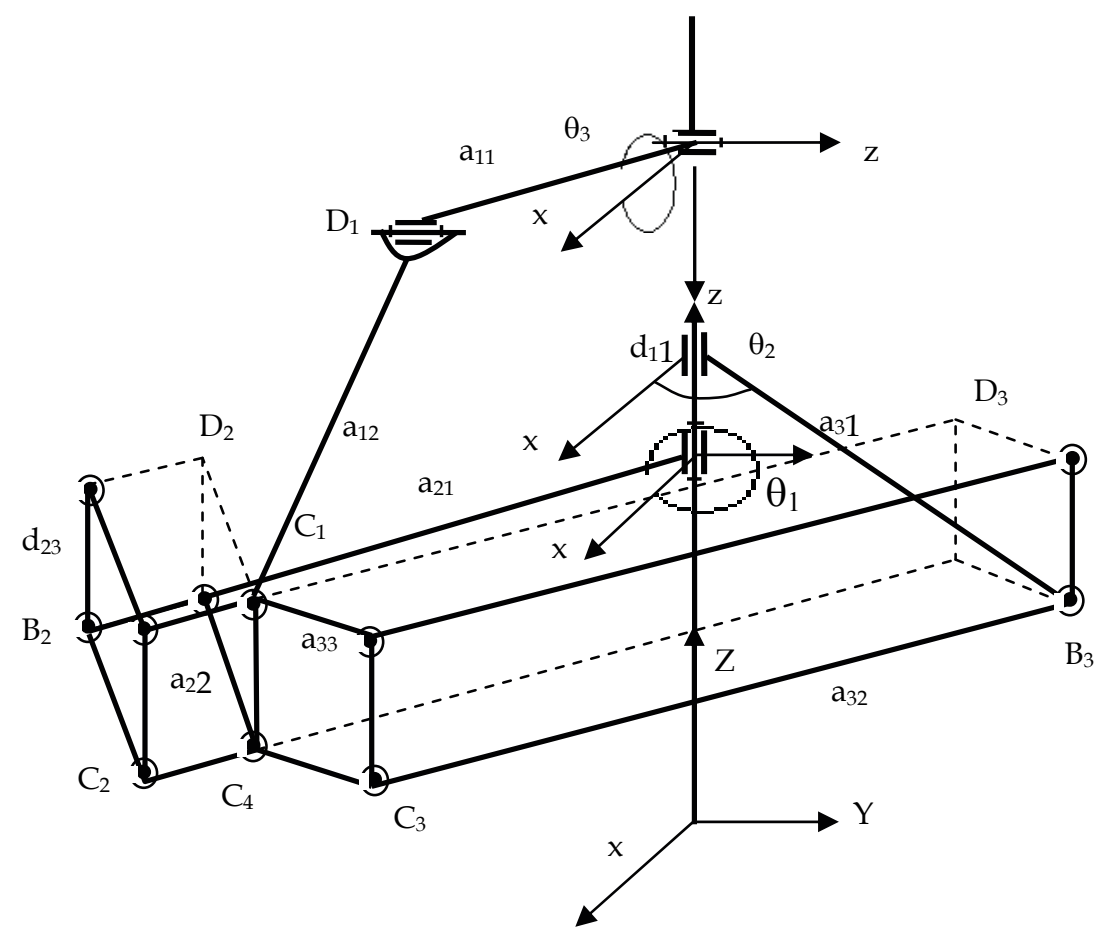

Fig. 3 Tau parallel mechanism

Coordinates of D1 are obtained as,

$$
\begin{gathered}
d_{1 x}=a_{11} \cos \left(\left(\theta_{1}+\theta_{2}\right) / 2\right) \cos \theta_{3} \\
d_{1 y}=a_{11} \cos \left(\left(\theta_{1}+\theta_{2}\right) / 2\right) \sin \theta_{3} \\
d_{1 z}=-a_{11} \sin \theta_{1}+d_{11} \\
c_{1 x}=p_{x} \\
c_{1 y}=p_{y} \\
c_{1 z}=p_{z}
\end{gathered}
$$

Where $\mathrm{P}_{\mathrm{x}}, \mathrm{P}_{\mathrm{y}}$, and $\mathrm{P}_{\mathrm{z}}$ are the coordinates of $\mathrm{C} 1$.

$$
\operatorname{dist}\left(d_{1}-c_{1}\right)=a_{12}
$$


Coordinates of D2 are obtained as,

$$
\begin{aligned}
& d_{2 x}=a_{21} \cos \left(\theta_{1}\right) \\
& d_{2 y}=a_{21} \sin \left(\theta_{1}\right) \\
& d_{2 z}=d_{21}+d_{23} \\
& c_{2 x}=p_{x} \\
& c_{2 y}=p_{y} \\
& c_{2 z}=p_{z}-d_{23} \\
& \operatorname{dist}\left(d_{2}-c_{1}\right)=a_{22}
\end{aligned}
$$

Coordinates of D3 are obtained as,

$$
\begin{gathered}
d_{3 x}=a_{31} \cos \left(\theta_{2}\right)-a_{33} \cos \left(120+\theta_{1}\right) \\
d_{3 y}=a_{31} \sin \left(\theta_{2}\right)-a_{33} \sin \left(120+\theta_{1}\right) \\
d_{3 z}=d_{31} \\
\operatorname{dist}\left(d_{3}-c_{1}\right)=a_{32}
\end{gathered}
$$

For inverse kinematics, simplify the Equation 2 and assume next expressions,

$$
\cos (\delta)=\frac{p_{x}}{\sqrt{p_{x}^{2}+p_{y}^{2}}}, \sin (\delta)=\frac{p_{y}}{\sqrt{p_{x}^{2}+p_{y}^{2}}}
$$

The new equation 5 a can be obtained from Equation 2.

$$
2 a_{21} \sqrt{p_{x}^{2}+p_{y}^{2}}\left(\frac{p_{x}}{\sqrt{p_{x}^{2}+p_{y}^{2}}} \cos \theta_{1}+\frac{p_{y}}{\sqrt{p_{x}^{2}+p_{y}^{2}}} \sin \theta_{1}\right)=a_{21}^{2}+\left(p_{x}^{2}+p_{y}^{2}+p_{z}^{2}\right)-a_{22}^{2}
$$

Then substitute the equation $4 \mathrm{a}$ into equation $5 \mathrm{a}$ to get

$$
\cos \left(\theta_{1}-\delta\right)=\frac{a_{21}^{2}+\left(p_{x}^{2}+p_{y}^{2}+p_{z}^{2}\right)-a_{22}^{2}}{2 a_{21} \sqrt{p_{x}^{2}+p_{y}^{2}}}
$$

Thus,

$$
\theta_{1}=\cos ^{-1}\left[\frac{a_{21}^{2}+\left(p_{x}^{2}+p_{y}^{2}+p_{z}^{2}\right)-a_{22}^{2}}{2 a_{21} \sqrt{p_{x}^{2}+p_{y}^{2}}}\right]+\delta
$$


where $\delta=\operatorname{tg}^{-1}\left(\frac{p_{y}}{p_{x}}\right)$

Assume next expressions as,

$$
p_{x}^{\prime}=p_{x}-a_{33} \cos \left(\theta_{1}+120\right) \quad \cos (\gamma)=\frac{p_{x}^{\prime}}{\sqrt{p_{x}^{\prime 2}+p_{y}^{\prime 2}}}
$$

Substitute the Equation 7a into Equation 3, the equation 8a can be obtained as,

$$
\theta_{2}=\cos ^{-1}\left[\frac{a_{31}^{2}-a_{32}^{2}+\left(p_{x}^{\prime 2}+p_{y}^{\prime 2}+p_{z}^{\prime 2}\right)-a_{22}^{2}}{2 a_{31} \sqrt{p_{x}^{\prime 2}+p_{y}^{\prime 2}}}\right]+\gamma
$$

where $\gamma=\operatorname{tg}^{-1}\left(\frac{p_{x}^{\prime}}{p_{y}^{\prime}}\right)$

Also the Equation 9a can be obtained by substituting the equation $6 a$, 8a into equation 1 .

$$
\theta_{3}=\cos ^{-1}\left[\frac{a_{11}^{2}+p_{x}^{2}+p_{y}^{2}+\left(p_{z}-d_{11}\right)^{2}-a_{12}^{2}}{2 \sqrt{\left[a_{11} \cos \left(\frac{\theta_{1}+\theta_{2}}{2}\right)+a_{11} \sin \left(\frac{\theta_{1}+\theta_{2}}{2}\right)\right]^{2}+\left(p_{z}-d_{11}\right)^{2}}}\right]-\phi
$$

where $\phi=\operatorname{tg}^{-1}\left[\frac{p_{z}-d_{11}}{a_{11} \cos \left(\frac{\theta_{1}+\theta_{2}}{2}\right)+a_{11} \sin \left(\frac{\theta_{1}+\theta_{2}}{2}\right)}\right]$

For forward kinematics, it is relatively easy. Subtractig equation 2 from Equation 1 for eliminating the square items $\left(p_{x}^{2}, p_{y}^{2}, p_{z}^{2}\right)$, then do the same procedure to Equation 2 and 3 , finally three linear equations can be obtained. The three length equations are applied to solve inverse and forward problems. A closed form solution can be obtained from the three equations for both inverse and forward problems.

\section{Jacobian matrix of TAU robot with all error parameters}

In error analysis, error sensitivity is represented by the Jacobian matrix. Derivation of the Jacobian matrix can be carried out after all the D-H models are established. For the TAU robot, the 3-DOF kinematic problem will become a 6-DOF kinematic problem. The kinematic problem becomes more complicated. 
In fact, the error sensitivity is formulated through $\frac{\partial x}{\partial g_{i}}, \frac{\partial y}{\partial g_{i}}, \frac{\partial z}{\partial g_{i}}$ where $\mathrm{x}, \mathrm{y}, \mathrm{z}$ represent the position of the tool plate and $d g_{i}$ is the error source for each component. So the following equations can be obtained:

$$
d x=\sum_{1}^{N} \frac{\partial x}{\partial l_{i}} d g_{i} \quad d y=\sum_{1}^{N} \frac{\partial y}{\partial l_{i}} d g_{i} \quad d z=\sum_{1}^{N} \frac{\partial z}{\partial l_{i}} d g_{i}
$$

The error model is actually a 6-DOF model since all error sources have been considered. It includes both the position variables $\mathrm{X}, \mathrm{Y}, \mathrm{Z}$ and also rotational angles $\alpha, \beta, \gamma$.

From the six kinematic chains, equations established based on D-H models are

$$
\begin{aligned}
& f_{1}=f_{1}(x, y, z, \alpha, \beta, \gamma, g)=0 \\
& f_{2}=f_{2}(x, y, z, \alpha, \beta, \gamma, g)=0 \\
& f_{6}=f_{6}(x, y, z, \alpha, \beta, \gamma, g)=0
\end{aligned}
$$

Differentiating all the equations against all the variables $x, y, z, \alpha, \beta, \gamma$ and $\mathrm{g}$, where $\mathrm{g}$ is a vector including all geometric parameters:

$$
\frac{\partial f_{i}}{\partial x} \cdot d x+\frac{\partial f_{i}}{\partial y} \cdot d y+\frac{\partial f_{i}}{\partial z} \cdot d z+\frac{\partial f_{i}}{\partial \alpha} \cdot d \alpha+\frac{\partial f_{i}}{\partial \beta} \cdot d \beta+\frac{\partial f_{i}}{\partial \gamma} \cdot d \gamma+\sum_{j} \frac{\partial f_{i}}{\partial g_{j}} \cdot d g_{j}=0
$$

Rewrite it in matrix as

$$
\left[\begin{array}{llllll}
\frac{\partial f_{1}}{\partial x} & \frac{\partial f_{1}}{\partial y} & \frac{\partial f_{1}}{\partial z} & \frac{\partial f_{1}}{\partial \alpha} & \frac{\partial f_{1}}{\partial \beta} & \frac{\partial f_{1}}{\partial \gamma} \\
\frac{\partial f_{2}}{\partial x} & \frac{\partial f_{2}}{\partial y} & \frac{\partial f_{2}}{\partial z} & \frac{\partial f_{2}}{\partial \alpha} & \frac{\partial f_{2}}{\partial \beta} & \frac{\partial f_{2}}{\partial \gamma} \\
\frac{\partial f_{3}}{\partial x} & \frac{\partial f_{3}}{\partial y} & \frac{\partial f_{3}}{\partial z} & \frac{\partial f_{3}}{\partial \alpha} & \frac{\partial f_{3}}{\partial \beta} & \frac{\partial f_{3}}{\partial \gamma} \\
\frac{\partial f_{4}}{\partial x} & \frac{\partial f_{4}}{\partial y} & \frac{\partial f_{4}}{\partial z} & \frac{\partial f_{4}}{\partial \alpha} & \frac{\partial f_{4}}{\partial \beta} & \frac{\partial f_{4}}{\partial \gamma} \\
\frac{\partial f_{5}}{\partial x} & \frac{\partial f_{5}}{\partial y} & \frac{\partial f_{5}}{\partial z} & \frac{\partial f_{5}}{\partial \alpha} & \frac{\partial f_{5}}{\partial \beta} & \frac{\partial f_{5}}{\partial \gamma} \\
\frac{\partial f_{6}}{\partial x} & \frac{\partial f_{6}}{\partial y} & \frac{\partial f_{6}}{\partial z} & \frac{\partial f_{6}}{\partial \alpha} & \frac{\partial f_{6}}{\partial \beta} & \frac{\partial f_{6}}{\partial \gamma}
\end{array}\right] \bullet\left[\begin{array}{c}
\sum_{j} \frac{-\partial f_{1}}{\partial g_{j}} d g_{j} \\
d y \\
d z \\
d \alpha \\
\sum_{j} \frac{-\partial f_{2}}{\partial g_{j}} d g_{j} \\
\sum_{j} \frac{-\partial f_{3}}{\partial g_{j}} d g_{j} \\
\sum_{j} \frac{-\partial f_{4}}{\partial g_{j}} d g_{j} \\
\sum_{j} \frac{-\partial f_{5}}{\partial g_{j}} d g_{j} \\
\sum_{j} \frac{-\partial f_{6}}{\partial g_{j}} d g_{j}
\end{array}\right]
$$


In a compact form, it becomes

$$
J_{1} d X=d G
$$

Where

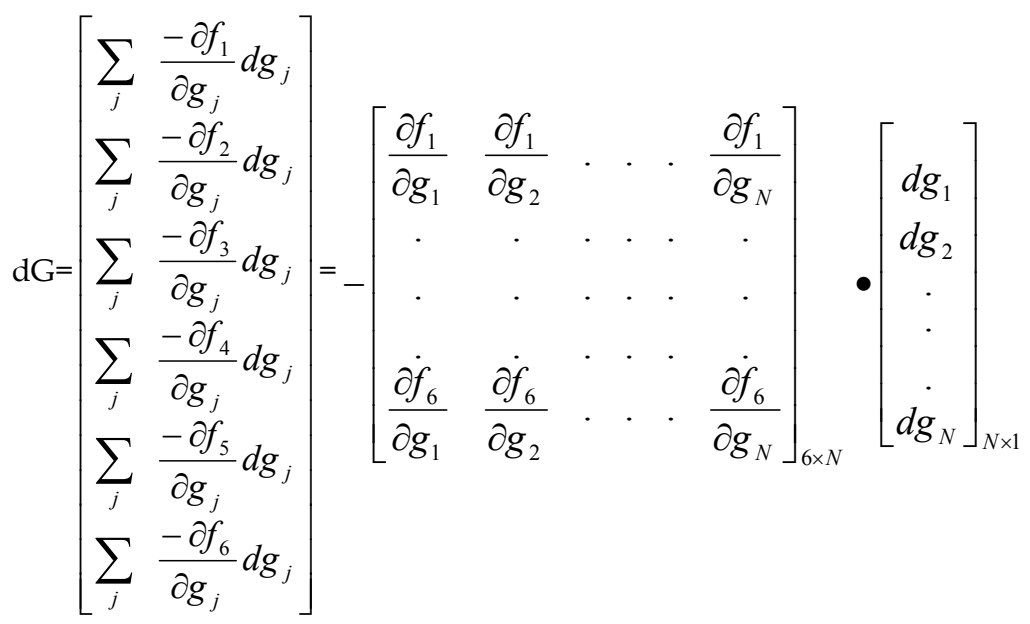

From Eq. (7) above, we have

$$
d G=J_{2} d g
$$

Substitute Eq.(6) into Eq.(8) to obtain

$$
\begin{aligned}
& J_{1} d X=J_{2} d g \\
& d X=\left(J_{1}^{-1} J_{2}\right) d g
\end{aligned}
$$

The Jacobian matrix is obtained as $J_{1}^{-1} \cdot J_{2}$

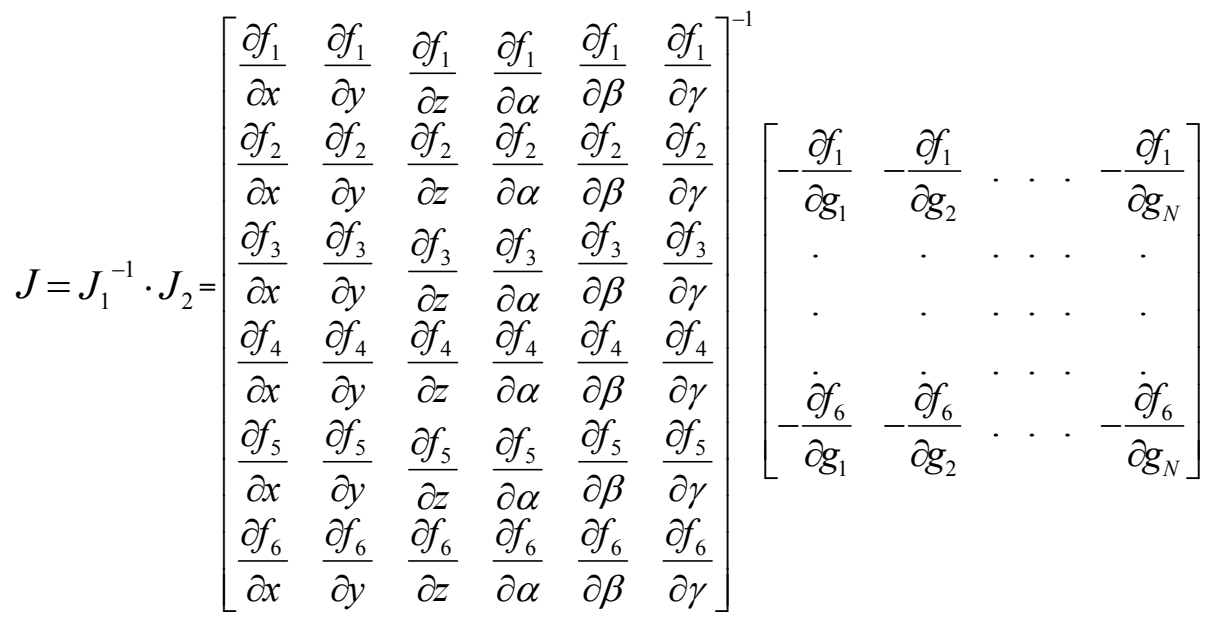


For a prototype of the TAU robotic design, the dimension of the Jacobian matrix is 6 by 71 . An analytical solution can be obtained and is used in our analysis.

\section{Kinematic modeling with all error parameters (application 1 of the Jacobian matrix)}

\subsection{Newton-Raphson numerical method}

Because of the number of parameters involved as well as the number of error sources involved, the kinematic problem becomes very complicated. No analytical solution can be obtained but numerical solution. The TAU configuration, as a special case of parallel robots, its forward kinematic problem is, therefore, very complicated. The Newton-Raphson method as an effective numerical method can be applied to calculate the forward problem of the TAU robot, with an accurate Jacobian matrix obtained.

Newton-Raphson method is represented by

$$
X_{n+1}=X_{n}-\left[F^{\prime}\left(X_{n}\right)\right]^{-1} \cdot F\left(X_{n}\right)
$$

With the six chain equations obtained before, the following can be obtained

$$
\left[F^{\prime}\left(X_{n}\right)\right]^{-1}=\operatorname{Inv}\left[\begin{array}{llllll}
\frac{\partial f_{1}}{\partial x} & \frac{\partial f_{1}}{\partial y} & \frac{\partial f_{1}}{\partial z} & \frac{\partial f_{1}}{\partial \alpha} & \frac{\partial f_{1}}{\partial \beta} & \frac{\partial f_{1}}{\partial \gamma} \\
\frac{\partial f_{2}}{\partial x} & \frac{\partial f_{2}}{\partial y} & \frac{\partial f_{2}}{\partial z} & \frac{\partial f_{2}}{\partial \alpha} & \frac{\partial f_{2}}{\partial \beta} & \frac{\partial f_{2}}{\partial \gamma} \\
\frac{\partial f_{3}}{\partial y} & \frac{\partial f_{3}}{\partial z} & \frac{\partial f_{3}}{\partial \alpha} & \frac{\partial f_{3}}{\partial \beta} & \frac{\partial f_{3}}{\partial \gamma} \\
\frac{\partial f_{4}}{\partial x} & \frac{\partial f_{4}}{\partial y} & \frac{\partial f_{4}}{\partial z} & \frac{\partial f_{4}}{\partial \alpha} & \frac{\partial f_{4}}{\partial \beta} & \frac{\partial f_{4}}{\partial \gamma} \\
\frac{\partial f_{5}}{\partial x} & \frac{\partial f_{5}}{\partial y} & \frac{\partial f_{5}}{\partial z} & \frac{\partial f_{5}}{\partial \alpha} & \frac{\partial f_{5}}{\partial \beta} & \frac{\partial f_{5}}{\partial \gamma} \\
\frac{\partial f_{6}}{\partial x} & \frac{\partial f_{6}}{\partial y} & \frac{\partial f_{6}}{\partial z} & \frac{\partial f_{6}}{\partial \alpha} & \frac{\partial f_{6}}{\partial \gamma}
\end{array}\right]
$$

This equation is used later to calculate the forward kinematic problem, and it is also compared with the method described in the next section.

\subsection{Jacobian approximation method}

A quick and efficient analytical solution is still necessary even though an accurate result has been obtained by the N-R method. The N-R result is produced based on iteration of numerical calculation, instead of from an analytical closed form solution. The N-R method is too slow in calculation to be used in on-line real time control. No certain solution is guaranteed in the N-R method. So a Jacobian approximation method is needed.

The Jacobian approximation method is established. Using this method, error analysis, calibration, compensation, and on-line control model can be established. As the TAU robot is based on a 3-DOF configuration, instead of a general Stewart platform, the Jacobian 
approximate modification can be obtained based the 3-DOF analytical solution without any errors. The mathematical description of the Jacobian approximation method can be described as follows.

For forward kinematics,

$$
\begin{aligned}
& X=F(\theta, \varepsilon) \\
& X=F(\theta, 0)+J_{\text {FORWARD }} \cdot d \varepsilon
\end{aligned}
$$

Where $J_{F O R W A R D}=F^{\prime}(\theta, \varepsilon)$ and $\varepsilon$ represents error.

Thus, the analytical solution $F(\theta, 0)$ and $F(X, 0)$, is obtained. Therefore, the Jacobian Approximation as an analytical solution is obtained and solving nonlinear equations using $\mathrm{N}-\mathrm{R}$ method is not necessary in this case.

\section{Determination of independent design variables using SVD method (application 2 of Jacobian matrix )}

With the reality that all the parts of a robot have manufacturing errors and misalignment errors as well as thermal errors, errors should be considered for any of the components in order to accurately model the accuracy of the robot. Error budget is carried out in the study and error sensitivity of robot kinematics with respect to any of the parameters can be obtained from the error modeling. This is realized through the established Jacobian matrix.

To find those parameters in the error model that are linearly dependent and those parameters that are difficult to observe, the Jacobian matrix is analyzed. SVD method (Singular Value Decomposition) is used in such an analysis.

A methodical way of determining which parameters are redundant is to investigate the singular vectors. An investigation of the last column of the $\mathrm{V}$ vector will reveal that some elements are dominant in order of magnitude. This implies that corresponding columns in the Jacobian matrix are linearly dependent. The work of reducing the number of error parameters must continue until no singularities exist and the condition number has reached an acceptable value.

A total of 40 redundant design variables of the 71 design parameters are eliminated by observing the numerical Jacobian matrix obtained. Table 2 in Appendix A lists the remaining calibration parameters.

\section{Error budget and results (application 3 of Jacobian matrix)}

When the SVD is completed and a linearly independent set of error model parameters determined, the Error Budget can be determined. The mathematical description of the error budget is as follows:

$$
\begin{aligned}
& J=U \bullet S \bullet V^{T} \\
& d X=J \bullet d g=U \bullet S \bullet V^{T} \bullet d g \\
& U^{T} \bullet d X=S \bullet V^{T} \bullet d g
\end{aligned}
$$


Assume $U^{T} \bullet d X=d \bar{X}$ and $V^{T} \bullet d g=d \bar{g}$. So we have $d \bar{g}=d \bar{X} / S_{i i}$, finally,

$$
d g=\left(V \bullet U^{T} \bullet d X\right) / S_{i i}
$$

Thus if the $\mathrm{dX}$ is given as the accuracy of the Tau robot, the error budget $\mathrm{dg}$ can be determined. Given the D-H parameters for all three upper arms and the main column, the locations of the joints located at each of the three upper arms are known accurately. The six chain equations are created for the six link lengths, as follows:

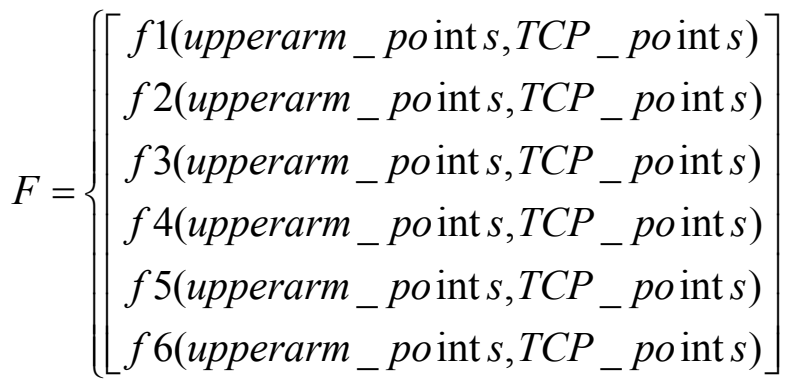

Where $T C P_{-}$point $=f(p x, p y, p z, \alpha, \beta, \gamma)$

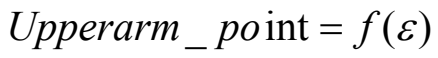

and $\varepsilon$ is a collection of all the design parameters. Thus,

$$
F=\left\{\begin{array}{l}
F 1(\varepsilon, p x, p y, p z, \alpha, \beta, \gamma) \\
F 2(\varepsilon, p x, p y, p z, \alpha, \beta, \gamma) \\
F 3(\varepsilon, p x, p y, p z, \alpha, \beta, \gamma) \\
F 4(\varepsilon, p x, p y, p z, \alpha, \beta, \gamma) \\
F 5(\varepsilon, p x, p y, p z, \alpha, \beta, \gamma) \\
F 6(\varepsilon, p x, p y, p z, \alpha, \beta, \gamma)
\end{array}\right]
$$

An error model is developed based on the system of equations as described above. A total of 71 parameters are defined to represent the entire system, the 71 parameters include all the $\mathrm{D}-\mathrm{H}$ parameters for the 3 upper arms, as well as the coordinates $(\mathrm{x}, \mathrm{y}, \mathrm{z})$ of the 6 points at both ends of the 6 links, respectively. Appendix B (Table 3) presents the error budget.

\section{Simulation results}

The Jacobian approximation method is verified by the following two different approaches: (1) 6-DOF forward kinematic analysis (Newton-Raphson method), and (2) ADAMS simulation results.

Fig. 4 shows the error between Jacobian approximation method and ADAMS simulation results, and Fig. 5 gives the error between the N-R method and ADAMS simulation results. 
In Fig. 4, the maximum error is $1.53 \mathrm{um}$ with an input error of $1 \mathrm{~mm}$. The Jacobian approximation method has a very high accuracy compared with simulation results.

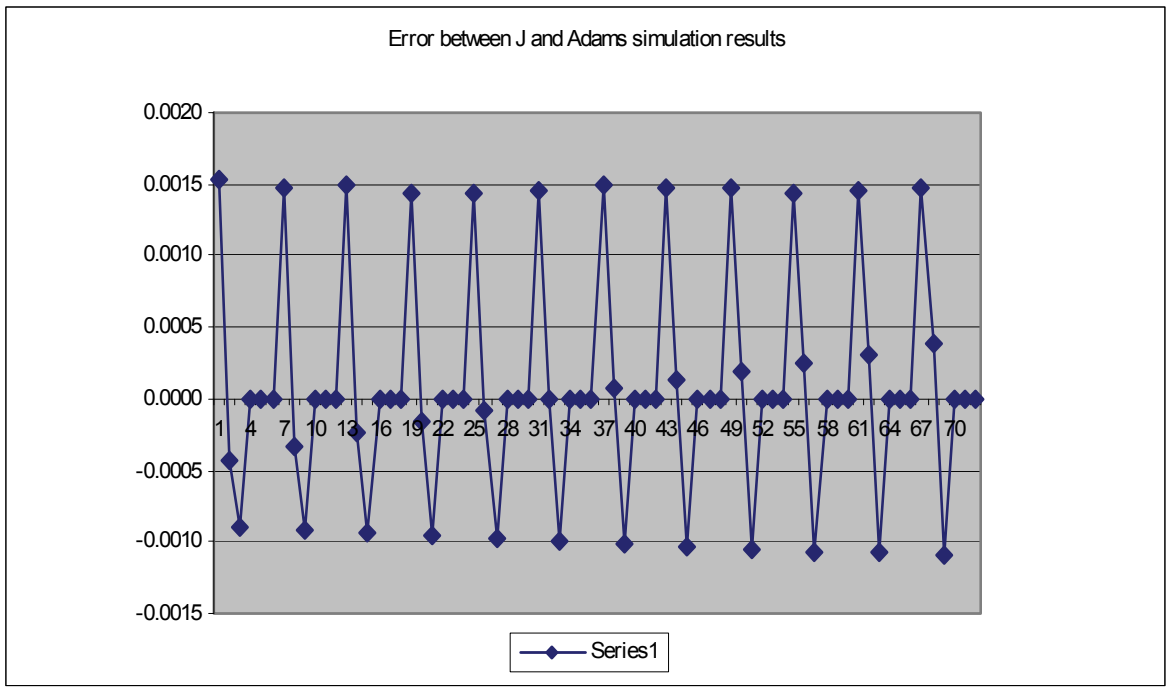

Fig. 4 Error between Jacobian approximation method and ADAMS simulation results

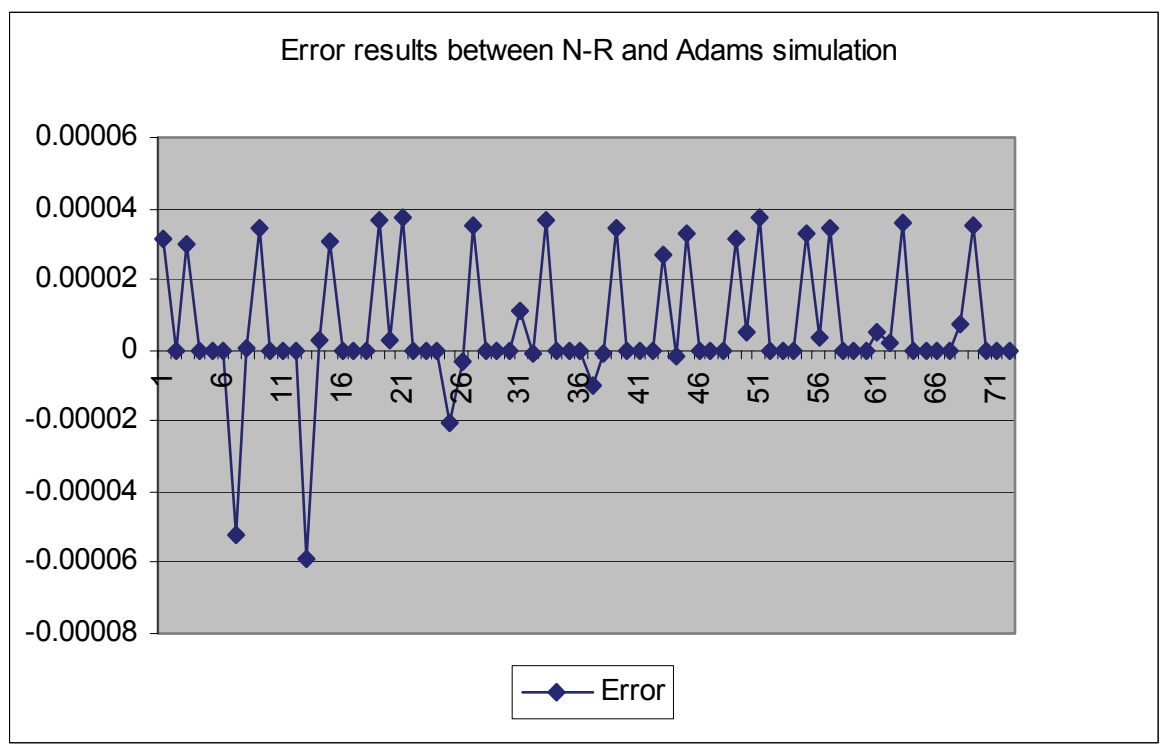

Fig. 5 Error between N-R method and ADAMS simulation results

Based on the D-H model of TAU with all error parameters, inverse and forward kinematic models have been established. From the point of view of mathematics, the TAU kinematic problem is to solve 6 nonlinear equations using Newton-Raphson method with Jacobian 
matrix as the searching direction and accurate results have been obtained up to $0.06 \mathrm{um}$ compared with ADAMS simulation results as shown in Fig. 5. Appendix C (Table 4) gives the comparison between Jacobian Matrix and N-R method.

\section{Conclusions}

It can be observed from the results, that Jacobian Matrix is effective with an accuracy up to $1.53 \mathrm{um}$ with an input error of $1 \mathrm{~mm}$ (Link 1 of lower arm 1). This was verified using ADAMS simulation results. Results from N-R method match very well with ADAMS simulation with a difference of only $0.06 \mathrm{um}$.

Based on the D-H model and an accurate Jacobian matrix, a series of results have been presented including error analysis, forward kinematic, redundant variable determination, error budget, and Jacobian approximation method. The Jacobian approximation method can be used in on-line control of the robot. For the TAU robot, a closed form solution of a forward kinematic problem is reached with a high accuracy instead of N-R numerical solution. The simulation results are almost perfect compared with that from ADAMS.

\section{Acknowledgement}

Authors from Stevens Institute of Technology are grateful to the ABB Corporate Research Center for the use of its research facilities and successful collaboration. ABB Corporate Research Center deeply appreciates the solid work done by Stevens's participants.

\section{References}

Brogangrdh, "Design of high performance parallel arm robots for industrial applications," Proceedings of A symposium Commemorating the Legacy, Works, and Life of Sir Robert Stawell Ball Upon the 100 th Anniversary of A Treatise on the Theory of Screws , University of Cambridge, Trinity College, July 9-11, 2000.

Brogangrdh, et al, "Device for relative movement of two elements," United States Patent 6425303, July 30, 2002.

Brogangrdh, et al, "Device for relative movement of two elements," United States Patent 6336374, January 8, 2002.

Brogangrdh, et al, "Device for relative movement of two elements," United States Patent 6301988, October 16, 2001.

Lung-wen Tsai "Robot Analysis-The Mechanics of Serial and Parallel Manipulators", John Wiley \& Sons, Inc.

M. Raghavan, "The Stewart Platform of General Geometry Has 40 Configurations," ASME Journal of Mechanical Design, June 1993, Vol. 115, pp 277-282.

Jian Wang and Oren Masory, "On the Accuracy of A Stewart Platform- Part I The Effect of Manufacturing Tolerances," IEEE, 1050-4729/ 1993, pp 114-120.

A. K. Dhingra, A. N. Almadi, D. Kohli, "Closed-Form Displacement Analysis of 8, 9 and 10Link Mechanisms," Mechanism and Machine Theory, 35, 2000, pp 821-850.

A. K. Dhingra, A. N. Almadi, D. Kohli, "A Grobner-Sylvester Hybrid Method For ClosedForm Displacement Analysis of Mechanisms," 1998 ASME Design Engineering Technical Conference, Atlanta, GA. 
A. K. Dhingra, A. N. Almadi, D. Kohli, “Closed-Form Displacement Analysis of 8, 9 and 10Link Mechanisms, Part II" Mechanism and Machine Theory, 35, 2000, pp 851-869.

Chunhe Gong, Jingxia Yuan, Jun Ni, "Nongeometric Error Identification and Compensation for Robotic System by Inverse Calibration," International Journal of Machine Tools \& Manufacture 40 (2000) 2119-2137.

M. Abderrahim, A. R. Whittaker, "Kinematic Model Identification of Industrial manipulators," Robotics and Computer Integrated Manufacturing 16 (2000), 1-8.

Amit J. Patel, Kornel F. Ehmann, "Calibration of a Hexapod Machine Tool Using a Redundant Leg," International Journal of Machine Tools \& Manufacture 40 (2000) 489-512.

Xiaolun Shi, R. G. Fenton, "A Complete and General Solution to the Forward Kinematics Problem of Platform-Type Robotic Manipulators," IEEE, 1050-4729/ 1994, pp 30553062.

Z. Jason Geng and Leonard S. Haynes, "A 3-2-1 Kinematic Configuration of a Stewart Platform and its Application to Six Degree of Freedom Pose Measurements," Robotics \& Computer-Integrated Manufacture, Vol. 11, No. 1, pp23-34, 1994.

Olivier Didrit, Michel Petitot, and Eric Walter "Guaranteed Solution of Direct Kinematic Problems for General Configurations of Parallel Manipulators," IEEE Transactions on Robotics and Automation, Vol. 14, No.2, April 1998.

Chang-de Zhang, Shin-Min Song, "Forward Kinematics of a Class of Parallel (Stewart) Platform with Closed-Form Solutions," Proceedings of the 1991 IEEE International Conference on Robotics and Automation, Sacramento, California-April 1991.

Prabjot Nanua, Kenneth J. Waldron, and Vasudeva Murthy, "Direct kinematic Solution of a Stewart platform," IEEE Transactions on Robotics and Automation, Vol. 6, No.4, August 1990.

S. V. Sreenivasan and K. J. Waldron, P. Nanua“Closed-Form Direct Displacement Analysis of a 6-6 Stewart Platform," Mech. Mach. Theory Vol. 29. No. 6, pp 855-864, 1994.

M. Griffis and J. Duffy, "A Forward Displacement Analysis of a Class of Stewart Platform," Journal of Robotic System 6 (6), 703-720 (1989) by John Wiley \& Sons, Inc.

W. Lin, M. Griffis, J. Duffy, "Forward Displacement Analyses of the 4-4 Stewart Platforms," Transaction of the ASME Vol. 114, September 1992, pp444-450. 


\section{Appendix A}

\begin{tabular}{|c|c|c|}
\hline Parameter Number & Parameter Definition & Parameter \\
\hline 16 & height of the TCP & $a$ \\
\hline 22 & joint 3 & a6 \\
\hline 23 & arm3 & a7 \\
\hline 24 & joint $1 \&$ arm 1 & d1 \\
\hline 25 & short arm 1 & d3 \\
\hline 28 & joint3 & d6 \\
\hline 31 & joint_link11_arm1 & $\mathrm{y1}$ \\
\hline 34 & joint_link21_arm1 & $\mathrm{y} 2$ \\
\hline 37 & joint_link31_arm1 & y3 \\
\hline 40 & joint_link12_arm2 & $\mathrm{y} 4$ \\
\hline 43 & joint_link22_arm2 & y5 \\
\hline 46 & joint_link13_arm3 & y6 \\
\hline 48 & joint_link11p & $\mathrm{x} 11$ \\
\hline 49 & joint_link11p & $\mathrm{y} 11$ \\
\hline 51 & joint_link31p & $x 22$ \\
\hline 52 & joint_link31p & $\mathrm{y} 22$ \\
\hline 54 & joint_link21p & $x 33$ \\
\hline 55 & joint_link21p & y33 \\
\hline 56 & joint_link21p & $z 33$ \\
\hline 57 & joint_link $12 p$ & $\mathrm{x} 44$ \\
\hline 58 & joint_link12p & y44 \\
\hline 59 & joint_link12p & z44 \\
\hline 60 & joint_link22p & $x 55$ \\
\hline 61 & joint_link22p & y55 \\
\hline 62 & joint_link22p & $z 55$ \\
\hline 63 & joint_link13p & $\mathrm{x} 66$ \\
\hline 64 & joint_link13p & y66 \\
\hline 67 & link11 & L1 \\
\hline 68 & link31 & L2 \\
\hline 69 & link21 & L3 \\
\hline 70 & link22 & L4 \\
\hline
\end{tabular}

Table. 2 List of the independent design variables

\section{Appendix B}

\begin{tabular}{|c|c|c|c|}
\hline \multicolumn{4}{|c|}{ Error Budget } \\
\hline Variable No. & Description & Name & Budget \\
\hline 1 & drive 1 & Joint 1 & 32 arcsec \\
\hline 2 & drive 2 & Joint 2 & 1.17 arcsec \\
\hline 3 & drive 3 & Joint 3 & 1.2 arcsec \\
\hline 17 & joint 1 and arm 1 & a1 & $1.62 \mathrm{um}$ \\
\hline
\end{tabular}




\begin{tabular}{|c|c|c|c|}
\hline 24 & & $\mathrm{~d} 1$ & 363 um \\
\hline 4 & & sit1 & 10.4 arcsec \\
\hline 10 & & afa1 & 110 arcsec \\
\hline 18 & joint_link11_arm 1 & $\mathrm{a} 2$ & 373 um \\
\hline 19 & \multirow{4}{*}{ short arm 1} & a3 & $174 \mathrm{um}$ \\
\hline 25 & & $\mathrm{~d} 3$ & 449 um \\
\hline 5 & & sit3 & 9.24 arcsec \\
\hline 11 & & afa3 & 9.45 arcsec \\
\hline 20 & \multirow{4}{*}{ joint 2 and arm 2} & $\mathrm{a} 4$ & $1.9 \mathrm{~mm}$ \\
\hline 26 & & $\mathrm{~d} 4$ & 485 um \\
\hline 6 & & sit4 & 1.22 arcsec \\
\hline 12 & & afa4 & 38.5 arcsec \\
\hline 21 & \multirow{4}{*}{ short arm 2} & a5 & $430 \mathrm{um}$ \\
\hline 27 & & d5 & $\mathrm{D}$ \\
\hline 7 & & sit5 & 11.2 arcsec \\
\hline 13 & & afa5 & $\mathrm{D}$ \\
\hline 22 & \multirow{4}{*}{ joint 3} & a6 & 0 \\
\hline 28 & & $\mathrm{~d} 6$ & $\mathrm{D}$ \\
\hline 8 & & sit6 & 4.64 arcsec \\
\hline 14 & & afa6 & $\mathrm{D}$ \\
\hline 23 & \multirow{4}{*}{$\operatorname{arm} 3$} & a7 & 0 \\
\hline 29 & & $\mathrm{~d} 7$ & $\mathrm{D}$ \\
\hline 9 & & sit7 & 6.14 arcsec \\
\hline 15 & & afa7 & $\mathrm{D}$ \\
\hline 30 & \multirow{3}{*}{ joint_link11_arm1 } & $\mathrm{x} 1$ & $\mathrm{D}$ \\
\hline 31 & & y1 & $43 \mathrm{um}$ \\
\hline 32 & & $\mathrm{z} 1$ & $123 \mathrm{um}$ \\
\hline 33 & \multirow{3}{*}{ joint_link21_arm1 } & $x 2$ & $\mathrm{D}$ \\
\hline 34 & & y2 & $49.4 \mathrm{um}$ \\
\hline 35 & & $\mathrm{z} 2$ & $\mathrm{D}$ \\
\hline 36 & \multirow{3}{*}{ joint_link31_arm1 } & $x 3$ & $115 \mathrm{um}$ \\
\hline 37 & & y3 & $108 \mathrm{um}$ \\
\hline 38 & & $\mathrm{z} 3$ & $\mathrm{D}$ \\
\hline 39 & \multirow{3}{*}{ joint_link12_arm2 } & $x 4$ & $\mathrm{D}$ \\
\hline 40 & & $\mathrm{y} 4$ & $1.28 \mathrm{~mm}$ \\
\hline 41 & & $\mathrm{z} 4$ & $\mathrm{D}$ \\
\hline 42 & \multirow{3}{*}{ joint_link22_arm2 } & $x 5$ & $2.6 \mathrm{~mm}$ \\
\hline 43 & & y5 & $68.2 \mathrm{um}$ \\
\hline 44 & & $\mathrm{z} 5$ & $\mathrm{D}$ \\
\hline 45 & \multirow{3}{*}{ joint_link13_arm3 } & $x 6$ & $\mathrm{D}$ \\
\hline 46 & & y6 & $21.6 \mathrm{um}$ \\
\hline 47 & & z6 & $213 \mathrm{um}$ \\
\hline 48 & \multirow[t]{2}{*}{ joint_link11_platform } & $\mathrm{x} 11$ & 50 um \\
\hline 49 & & y11 & $50 \mathrm{um}$ \\
\hline
\end{tabular}




\begin{tabular}{|c|c|c|c|}
\hline 50 & & z11 & $\mathrm{D}$ \\
\hline 51 & \multirow{3}{*}{ joint_link31_platform } & $x 22$ & $50 \mathrm{um}$ \\
\hline 52 & & y22 & $50 \mathrm{um}$ \\
\hline 53 & & $\mathrm{z} 22$ & $\mathrm{D}$ \\
\hline 54 & \multirow{3}{*}{ joint_link21_platform } & $x 33$ & $50 \mathrm{um}$ \\
\hline 55 & & y33 & $50 \mathrm{um}$ \\
\hline 56 & & $\mathrm{z} 33$ & $13.3 \mathrm{um}$ \\
\hline 57 & \multirow{3}{*}{ joint_link12_platform } & $x 44$ & $50 \mathrm{um}$ \\
\hline 58 & & $\mathrm{y} 44$ & $50 \mathrm{um}$ \\
\hline 59 & & $\mathrm{z} 44$ & $37.9 \mathrm{um}$ \\
\hline 60 & \multirow{3}{*}{ joint_link22_platform } & $x 55$ & $50 \mathrm{um}$ \\
\hline 61 & & y55 & $50 \mathrm{um}$ \\
\hline 62 & & $\mathrm{z} 55$ & 398 um \\
\hline 63 & \multirow{3}{*}{ joint-link13_platform } & $x 66$ & $50 \mathrm{um}$ \\
\hline 64 & & y66 & $50 \mathrm{um}$ \\
\hline 65 & & z66 & $50 \mathrm{um}$ \\
\hline 16 & height of the TCP & $\mathrm{a}$ & 436 um \\
\hline 66 & link 13 & L0 & 0 \\
\hline 67 & link 11 & L1 & $88 \mathrm{um}$ \\
\hline 68 & link 31 & L2 & $151 \mathrm{um}$ \\
\hline 69 & link 21 & L3 & $54.3 \mathrm{um}$ \\
\hline 70 & link 22 & L4 & $213 \mathrm{um}$ \\
\hline 71 & link 12 & L5 & $1.47 \mathrm{~mm}$ \\
\hline
\end{tabular}

Table 3 Error budget

\section{Appendix C}

\begin{tabular}{|c|c|c|c|c|}
\hline Drive Angles & TCP Pose & Jacobian & Newton_raphson & Error between $\mathrm{J}$ and $\mathrm{N}$ \\
\hline \multirow{6}{*}{$\begin{array}{l}\text { joint } 1=0 \\
\text { joint } 2=0 \\
\text { joint } 3=0\end{array}$} & $\mathrm{X}$ & $0.00 E+00$ & $1.53 E-03$ & 0.001531339 \\
\hline & $\bar{Y}$ & $-1.81 E+00$ & $-1.81 E+00$ & -0.0049559 \\
\hline & $\bar{Z}$ & $-1.61 \mathrm{E}-16$ & $-9.20 E-04$ & -0.000919889 \\
\hline & afa & $5.01 \mathrm{E}-03$ & $5.01 \mathrm{E}-03$ & $2.634 \mathrm{E}-07$ \\
\hline & bta & $-9.32 \mathrm{E}-19$ & $-9.33 E-19$ & $-1.00679 \mathrm{E}-21$ \\
\hline & gma & $-9.32 E-19$ & $-9.32 E-19$ & $-1.5976 E-22$ \\
\hline \multirow{6}{*}{$\begin{array}{c}\text { joint } 1=3.75 \\
\text { joint } 2=3.75 \\
\text { joint } 3=2\end{array}$} & $\mathrm{X}$ & 1.19E-01 & $1.20 \mathrm{E}-01$ & 0.00119916 \\
\hline & $\bar{Y}$ & $-1.81 E+00$ & $-1.81 E+00$ & -0.0009736 \\
\hline & $z$ & $-2.09 \mathrm{E}-16$ & $-9.45 E-04$ & -0.000945048 \\
\hline & afa & $5.01 \mathrm{E}-03$ & $5.01 \mathrm{E}-03$ & $2.7566 \mathrm{E}-06$ \\
\hline & bta & $0.00 E+00$ & $9.46 \mathrm{E}-16$ & $9.45683 E-16$ \\
\hline & $\mathrm{gma}$ & $0.00 E+00$ & $-4.84 E-16$ & $-4.84153 E-16$ \\
\hline \multirow{6}{*}{$\begin{array}{c}\text { joint } 1=7.5 \\
\text { joint } 2=7.5 \\
\text { joint } 3=4\end{array}$} & $x$ & $2.37 E-01$ & $2.38 \mathrm{E}-01$ & 0.00135537 \\
\hline & $\bar{Y}$ & $-1.80 E+00$ & $-1.80 E+00$ & 0.0007562 \\
\hline & $\mathrm{Z}$ & $-1.79 E-16$ & $-9.69 E-04$ & -0.000968876 \\
\hline & afa & $5.02 \mathrm{E}-03$ & $5.02 \mathrm{E}-03$ & $3.547 \mathrm{E}-07$ \\
\hline & bta & $0.00 E+00$ & $3.15 E-16$ & $3.14853 E-16$ \\
\hline & gma & $0.00 E+00$ & $-4.82 E-16$ & $-4.82129 E-16$ \\
\hline
\end{tabular}




\begin{tabular}{|c|c|c|c|c|}
\hline \multirow{6}{*}{$\begin{array}{c}\text { joint } 1=11.25 \\
\text { joint } 2=11.25 \\
\text { joint } 3=6\end{array}$} & $\mathrm{X}$ & $3.54 \mathrm{E}-01$ & $3.55 \mathrm{E}-01$ & 0.00149511 \\
\hline & $Y$ & $-1.78 E+00$ & $-1.78 E+00$ & 0.0001837 \\
\hline & Z & $-1.79 E-16$ & $-9.91 \mathrm{E}-04$ & -0.000991397 \\
\hline & afa & $5.03 E-03$ & $5.03 E-03$ & $3.263 E-06$ \\
\hline & bta & $0.00 E+00$ & $-3.10 E-18$ & $-3.10077 E-18$ \\
\hline & $\mathrm{gma}$ & $-9.32 E-19$ & $1.15 E-18$ & $2.0782 E-18$ \\
\hline \multirow{6}{*}{$\begin{array}{c}\text { joint } 1=15 \\
\text { joint } 2=15 \\
\text { joint } 3=8\end{array}$} & $x$ & $4.70 E-01$ & $4.71 \mathrm{E}-01$ & 0.00111796 \\
\hline & $Y$ & $-1.75 E+00$ & $-1.75 E+00$ & -0.0027737 \\
\hline & $z$ & $-5.96 E-17$ & $-1.01 \mathrm{E}-03$ & -0.001012624 \\
\hline & afa & $5.05 E-03$ & $5.05 E-03$ & $1.7286 \mathrm{E}-06$ \\
\hline & bta & $0.00 E+00$ & $0.00 E+00$ & 0 \\
\hline & $\mathrm{gma}$ & $0.00 E+00$ & $0.00 E+00$ & 0 \\
\hline \multirow{6}{*}{$\begin{array}{c}\text { joint } 1=18.75 \\
\text { joint } 2=18.75 \\
\text { joint } 3=10\end{array}$} & $\mathrm{X}$ & $5.83 E-01$ & $5.85 E-01$ & 0.00173003 \\
\hline & $\bar{Y}$ & $-1.72 E+00$ & $-1.72 E+00$ & 0.0017688 \\
\hline & z & $-5.96 \mathrm{E}-17$ & $-1.03 E-03$ & -0.001032565 \\
\hline & afa & $5.07 E-03$ & $5.08 E-03$ & $6.0465 E-06$ \\
\hline & bta & $4.66 \mathrm{E}-19$ & $-6.39 E-16$ & $-6.39425 E-16$ \\
\hline & gma & $-9.32 E-19$ & $9.59 \mathrm{E}-16$ & $9.6015 E-16$ \\
\hline \multirow{6}{*}{$\begin{aligned} \text { joint } 1 & =22.5 \\
\text { joint } 2 & =22.5 \\
\text { joint } 3 & =12\end{aligned}$} & $\mathrm{X}$ & $6.94 \mathrm{E}-01$ & $6.96 \mathrm{E}-01$ & 0.00184612 \\
\hline & $\mathrm{Y}$ & $-1.68 E+00$ & $-1.68 E+00$ & 0.0036642 \\
\hline & $z$ & $2.09 E-16$ & $-1.05 E-03$ & -0.00105122 \\
\hline & afa & $5.11 \mathrm{E}-03$ & $5.11 \mathrm{E}-03$ & $-3.4323 E-06$ \\
\hline & bta & $0.00 E+00$ & $-8.47 E-22$ & $-8.47033 E-22$ \\
\hline & $\mathrm{gma}$ & $0.00 E+00$ & $8.47 E-22$ & $8.47033 E-22$ \\
\hline \multirow{6}{*}{$\begin{array}{c}\text { joint } 1=26.25 \\
\text { joint } 2=26.25 \\
\text { joint } 3=14\end{array}$} & $x$ & $8.03 E-01$ & $8.04 \mathrm{E}-01$ & 0.00099179 \\
\hline & $\bar{Y}$ & $-1.63 E+00$ & $-1.63 E+00$ & 0.002734 \\
\hline & $z$ & $0.00 E+00$ & $-1.07 \mathrm{E}-03$ & -0.001068582 \\
\hline & afa & $5.14 \mathrm{E}-03$ & $5.14 \mathrm{E}-03$ & $3.7091 \mathrm{E}-06$ \\
\hline & $\mathrm{bta}$ & $0.00 E+00$ & $3.26 \mathrm{E}-16$ & $3.25672 \mathrm{E}-16$ \\
\hline & gma & $0.00 E+00$ & $-4.78 E-16$ & $-4.77901 E-16$ \\
\hline \multirow{6}{*}{$\begin{array}{l}\text { joint } 1=30 \\
\text { joint } 2=30 \\
\text { joint } 3=16\end{array}$} & $x$ & $9.07 \mathrm{E}-01$ & $9.09 E-01$ & 0.00170544 \\
\hline & $\bar{Y}$ & $-1.57 E+00$ & $-1.57 E+00$ & -0.0012306 \\
\hline & $z$ & $-2.09 E-16$ & $-1.08 E-03$ & -0.001084643 \\
\hline & afa & $5.19 E-03$ & $5.19 E-03$ & $-2.0346 E-06$ \\
\hline & bta & $0.00 E+00$ & $8.47 E-22$ & $8.47033 \mathrm{E}-22$ \\
\hline & $\mathrm{gma}$ & $0.00 E+00$ & $0.00 E+00$ & 0 \\
\hline \multirow{6}{*}{$\begin{array}{c}\text { joint } 1=33.75 \\
\text { joint } 2=33.75 \\
\text { joint } 3=18\end{array}$} & $x$ & $1.01 \mathrm{E}+00$ & $1.01 E+00$ & -0.0004597 \\
\hline & $\mathrm{Y}$ & $-1.51 E+00$ & $-1.51 E+00$ & 0.0015319 \\
\hline & Z & $1.49 E-16$ & $-1.10 E-03$ & -0.001099391 \\
\hline & afa & $5.24 E-03$ & $5.24 \mathrm{E}-03$ & $-7.54 E-08$ \\
\hline & bta & $0.00 E+00$ & $-6.75 E-16$ & $-6.74923 E-16$ \\
\hline & gma & $0.00 E+00$ & $4.55 E-18$ & $4.54772 E-18$ \\
\hline \multirow{6}{*}{$\begin{array}{c}\text { joint } 1=37.5 \\
\text { joint } 2=37.5 \\
\text { joint } 3=18\end{array}$} & $\mathrm{X}$ & $1.10 E+00$ & $1.11 \mathrm{E}+00$ & 0.0060663 \\
\hline & $\mathrm{Y}$ & $-1.44 E+00$ & $-1.44 E+00$ & 0.0007547 \\
\hline & $z$ & $2.98 E-17$ & $-1.11 \mathrm{E}-03$ & -0.001112819 \\
\hline & afa & $5.30 E-03$ & $5.30 E-03$ & $2.869 E-07$ \\
\hline & $\mathrm{bta}$ & $0.00 E+00$ & $0.00 E+00$ & 0 \\
\hline & $\mathrm{gma}$ & $0.00 E+00$ & $0.00 E+00$ & 0 \\
\hline \multirow{6}{*}{$\begin{array}{c}\text { joint } 1=41.25 \\
\text { joint } 2=41.25 \\
\text { joint } 3=22\end{array}$} & $\mathrm{X}$ & $1.20 E+00$ & $1.20 E+00$ & -0.002128 \\
\hline & $\bar{Y}$ & $-1.36 \mathrm{E}+00$ & $-1.36 \mathrm{E}+00$ & -0.0038563 \\
\hline & $\mathrm{z}$ & $-2.98 E-17$ & $-1.12 \mathrm{E}-03$ & -0.001124931 \\
\hline & afa & $5.37 E-03$ & $5.37 \mathrm{E}-03$ & $-1.1 \mathrm{E}-07$ \\
\hline & bta & $0.00 E+00$ & $0.00 E+00$ & 0 \\
\hline & $\mathrm{gma}$ & $0.00 E+00$ & $0.00 E+00$ & 0 \\
\hline
\end{tabular}

Table 4 Results of the comparison between Jacobian Matrix and N-R method 


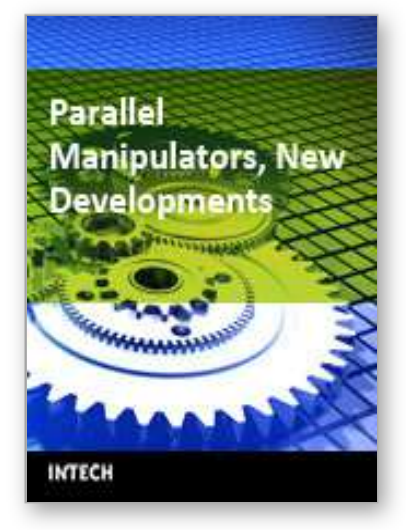

\author{
Parallel Manipulators, New Developments \\ Edited by Jee-Hwan Ryu
}

ISBN 978-3-902613-20-2

Hard cover, 498 pages

Publisher I-Tech Education and Publishing

Published online 01, April, 2008

Published in print edition April, 2008

Parallel manipulators are characterized as having closed-loop kinematic chains. Compared to serial manipulators, which have open-ended structure, parallel manipulators have many advantages in terms of accuracy, rigidity and ability to manipulate heavy loads. Therefore, they have been getting many attentions in astronomy to flight simulators and especially in machine-tool industries. The aim of this book is to provide an overview of the state-of-art, to present new ideas, original results and practical experiences in parallel manipulators. This book mainly introduces advanced kinematic and dynamic analysis methods and cutting edge control technologies for parallel manipulators. Even though this book only contains several samples of research activities on parallel manipulators, I believe this book can give an idea to the reader about what has been done in the field recently, and what kind of open problems are in this area.

\title{
How to reference
}

In order to correctly reference this scholarly work, feel free to copy and paste the following:

Hongliang Cui, Zhenqi Zhu, Zhongxue Gan and Torgny Brogardh (2008). Error Modeling and Accuracy of TAU Robot, Parallel Manipulators, New Developments, Jee-Hwan Ryu (Ed.), ISBN: 978-3-902613-20-2, InTech, Available from:

http://www.intechopen.com/books/parallel_manipulators_new_developments/error_modeling_and_accuracy_o f_tau_robot

\section{INTECH}

open science | open minds

\author{
InTech Europe \\ University Campus STeP Ri \\ Slavka Krautzeka 83/A \\ 51000 Rijeka, Croatia \\ Phone: +385 (51) 770447 \\ Fax: +385 (51) 686166 \\ www.intechopen.com
}

\author{
InTech China \\ Unit 405, Office Block, Hotel Equatorial Shanghai \\ No.65, Yan An Road (West), Shanghai, 200040, China \\ 中国上海市延安西路65号上海国际贵都大饭店办公楼 405 单元 \\ Phone: +86-21-62489820 \\ Fax: +86-21-62489821
}


(C) 2008 The Author(s). Licensee IntechOpen. This chapter is distributed under the terms of the Creative Commons Attribution-NonCommercialShareAlike-3.0 License, which permits use, distribution and reproduction for non-commercial purposes, provided the original is properly cited and derivative works building on this content are distributed under the same license. 